\title{
RURAL HEALTH SERVICES: DATA, TECHNOLOGY AND THE SOCIAL CAPITAL OF LOCAL HEALTH PROFESSIONALS, TIME TO INVEST!
}

\author{
David S Briggs
}

Recent editorials have had some focus on health policy and health reform and included commentary about the variability of output from public policy research institutes, based on their respective philosophical and ideological position. Recently, a group Global Access Partners (GAP) published a report entitled 'Australia's Health 2040: GAP Taskforce Report'. [1] This organisation is said to be an independent non-profit institute, established in 1997 and is a member of the TCG Group, described as a diverse and growing network of Australian-owned companies. [1,2]

The Task Force Report suggests seven reforms to provide consumers with the right type of care. These reforms include; increased emphasis on prevention and chronic disease management, funding equitable access to a patient-centred delivery model, implementation of all independent MBS reviews creating an ongoing process to identify low value care opportunities. The detail of these reforms is included in the Report. [1, p.4] The suggested reforms also include investment in the utilisation of technology in primary care, providing effective care for dentistry and supporting the utilisation of mental health services, including digital services. [1, p.5] The Report also suggests that 'paying the right price for care' requires a private-public partnership structure and that the price paid be benchmarked to the value demonstrated. [1, p. 6]

In operating transparently and efficiently the Report argues for a National Centre for Healthcare Innovation and Improvement. In part they suggest this might help build capacity in the commissioning work of Primary Health Networks. There are, of course, further recommendations and the Report is commended to you and you are encouraged to read further. The Report emphasises that the reforms are 'proposed through a pragmatic lens' based on 'context, experience and international best practice'. [1, p.9] The Report also identifies the inequity of access for rural and remote communities to access care and general practice based primary healthcare. [1, p.11] This, in the authors view are very pertinent current sensitivities given the extensive drought in rural areas and the extensive bush fire grounds many of us are experiencing in Australia.

It suggests to the Editor that any drought/fire strategies and funding adopted to help address the impact of drought and fire on communities should include an additional major investment in both structure and social capital in primary health care in what are basically 'underserved' rural contexts. The lack of equity for rural communities in accessing and utilising healthcare is more than self-evident. Poor socio-economic determinants and significant gaps in general practitioners and allied health staff go to a lack of social capital in rural communities. Restoring the health of rural communities should be a drought priority response. The Report emphasises that 'healthcare is a major employer and driver of economic activity in Australia'. [1, p.14]

The Task Force Report goes on to suggest trends that will influence future health service development. One of these is the growing role of technology and data. Unfortunately, in Australia, this growth has been limited by poor communication infrastructure and strictures on payment methods for general practice consultations using technology. The impact in primary care is limited although telemedicine is more accessible in the emergency departments of acute care hospitals, giving patients and staff instant access to emergency physicians and other specialists. This access has not been extended to the rural primary healthcare sector in any substantial way. 
This contrasts with the recent experience of this Editor in presenting at and attending a health conference in Shanghai, China. The integrated traditional and western medicine private hospitals who hosted the conference were focused on technology, they already have and are using 5G, they have Robots that can diagnose and treat and they are looking at their 'big data' to evaluate and improve the quality of health outcomes. The conference had a panel session of senior doctors reflecting and debating what the future of their profession might be given the implementation of technology and robotics. The statement was made at this conference that the patient and doctor no longer need to be in the same room at the same time for diagnosis and treatment to occur! [3]

In the USA, one example of attempts to address the void in rural and remote America is described as a 'telemedicine centre' where physicians for one provider are said to work out of 'high tech cubicles' not traditional treatment rooms, to provide remote emergency care for 179 hospitals across 30 states! This 'virtual ER' is located in a suburban industrial park and responds remotely to more than 15,000 emergencies each year, using remote - controlled cameras and computer screens. This article goes on to suggest that if anything defines the growing health gap between rural and urban America, it is the rise of emergency telemedicine in the poorest, sickest and most remote parts of the country, where the choice is increasingly to have a doctor on screen or no doctor at all'. [4]

These are just two examples of innovation in rural healthcare, albeit in different political and public policy contexts to that of Australia. However, it does raise the question as to the effectiveness of the organisation of health services that still reside in a public policy and political context that has not really changed since 1901. Do we really need all of those State health bureaucracies as well as those maintained by the Commonwealth? Other examples of more ordered national health systems in the Asia Pacific would suggest not.

However, returning to the present, not the future, the Commonwealth and State governments will turn attention to rebuilding rural communities following the drought and bushfires. Rural communities are resilient, but they have lost a lot of social capital. In our case I'm defining that as general practitioners, nurses and the range of allied health professionals. A greater investment in attracting these resources to rural communities or groups of communities with appropriate technologies giving them access to specialist services directly would be a wise investment. The existing approaches have not worked nor is the oft used practices of noting the poorer health outcomes of rural dwellers, shaking our heads but substantially not making any effective progress within existing structures, to address them.

Let us hear of innovative approaches and partnerships and use the opportunity of rebuilding rural communities, post the drought and fires, to also include a greater investment in their health services.

\section{DS Briggs}

Editor in Chief

NB: The Editor is a member of a PHN Board

\section{References}

1. Global Access Partners. (2019). Ensuring the Sustainability of the Australian Health System Australia's Health 2040 Taskforce Report. Accessed 20th November 2019 and available from https://www.globalaccesspartners.org/AustraliaHealth 2040_GAPTaskforceReport_Jul2019.pdf. Sydney.

2. TCG Group of Companies. Access available from http://www.tcg.net.au/history.html. Sydney

3. Briggs, DS 2019. Latest trends, concepts and Practice in health management. Presentation at the International Conference \& China's Hospital Competitive Conference. 19-22nd September, Shanghai Sevenths People's Hospital. Shanghai.

4. Saslow, E. (2019). The most remote emergency room: Life and death in rural America. The Washington Post 17th November 2019. Available at https://www.washingtonpost.com/national/the-mostremote-emergency-room/2019/11/16/717d08e2-063e1 lea-b17d-8b867891d39d_story.html. 